\title{
Rivalry between human ideation and virus mutation: two competing means of sustainability
}

\author{
Pascal J. Goldschmidt-Clermont ${ }^{1}$, Alexander J.P. Goldschmidt ${ }^{2}$, Roy E. Weiss ${ }^{3}$ \\ ${ }^{1}$ Alzady International LLC, Dean Emeritus, Professor of Medicine Emeritus, Miller School of Medicine University of Miami, Miami, Florida 33136. \\ ${ }^{2}$ Alzady International LLC, Miami, USA. \\ ${ }^{3}$ University of Miami Leonard M. Miller School of Medicine, Department of Medicine Chairman, Miami, USA. \\ *Corresponding Author: Pascal J Goldschmidt-Clermont, Alzady International LLC, Dean Emeritus, Professor of Medicine Emeritus, Miller \\ School of Medicine University of Miami, Miami, Florida 33136, USA.
}

Received Date: April 16.2021; Accepted Date: April 29, 2021; Published Date: May 12, 2021

Citation: Pascal J. Goldschmidt-Clermont, Alexander J.P. Goldschmidt, Roy E. Weiss, (2021) Rivalry between Human Ideation and Virus Mutation: Two Competing Means of Sustainability. J Women Health Care Issues, 4(3); Doi:10.31579/2642-9756/058

Copyright: (92021 Pascal J Goldschmidt-Clermont, This is an open-access article distributed under the terms of the Creative Commons Attribution License, which permits unrestricted use, distribution, and reproduction in any medium, provided the original author and source are credited.

\begin{abstract}
For the first time in human history, obtaining a COVID-19 vaccine has become essential for the sustainability of our species. As an amazing product of collective ideation, remarkably safe and efficient vaccines have been invented, tested, distributed, and administered to the population on a voluntary basis. The fast-mutating individual behavior of the virus is probably guided by a similar goal of the sustainability of the species. With this commentary, we analyze and compare two means of sustainability through adaptability: collective ideation in the case of humans and individual mutations in the case of viruses - two very different species whose behaviors are driven by sustainability.
\end{abstract}

Keywords: sustainability; covid-19; vaccine; genetic surveillance; mutation; ideation; consumer behavior

\section{Introduction}

"It is not the most intellectual of the species that survives; it is not the strongest that survives; but the species that survives is the one that is able best to adapt and adjust to the changing environment in which it finds itself”. Darwin's Origin of Species

It is obvious that humans have little in common with viruses, except, perhaps, for an exceptional ability to adapt. Indeed, viruses have been on earth for 3.5 billion years, whereas for humans, our earliest ancestors appeared 7 million years ago, meaning that viruses have been around 500 times longer. Humans are complex organisms made of cells, tissues, organs, and bodies that are fully capable of reproducing via sexual reproduction. Viruses are single units, a quadrillion times smaller than an adult human, incapable of reproduction in the absence of a suitable host cell. However, they are known to cause some of the worst pandemics, while humans, thus far, have survived all pandemics they have been exposed to. Humans, unlike other forms of life on earth, including viruses, which adapt to their environment, adapt the environment to themselves, often at the expense of other species; thus protecting their vulnerabilities from things that they are unable to control. Hence, we humans could not be more different from viruses, except that we use similar tools (nanotools from nature such as enzymes and nucleic acids) and share a keen ability to adapt to a rapidly changing environment.

\section{Mutation versus Ideation for Adaptation}

Viruses strive through mutation: good examples are the UK B.1.1.17, South Africa B.1.351, and Brazil P.1 variants of SARS-CoV-2, the virus that is causing the current COVID-19 pandemic [1]. Human cells do not typically mutate fast and most do not mutate at all except memory B cells, which do so to fight pathogens more effectively [2]. Instead, to adapt to pathogen changes and too many other afflictions, humans survive and thrive via ideation rather than mutation [3]. While artificial intelligence is evolving rapidly, humankind's ability to respond to threatening stressors depends entirely on their most sophisticated form of ideation.

A viral mutation occurs and, if beneficial, is propagated from the act of one virus, expanded, and perpetuated. By contrast, the essence of what makes us human is that human ideation requires a society of people working towards the same goal and is interdependent on socialization. Viruses mutate alone, humans ideate as a society, and even when a transforming idea is ascribed to one particular individual, the opportunity for such ideation was created by a society of fellow humans.

\section{Mutation and Ideation Similarities}

There are interesting parallels between ideation and mutation. Although mutation is a chemical reaction and ideation is an electrochemical reaction, both occur in a particular context, preceded by other instances of ideation or mutation, and likely followed by more instances of ideation and mutation. There is a stochastic factor to both ideation and mutation. The discoveries of vaccination, radiation, and penicillin were the result of coincidental ideation events. In fact, most original ideas do not result in a change in our adaptability. Similarly, mutations seem to occur as 
stochastic events whereby only a very few can promote virus adaptation, which itself is often molded by the type of host being infected, vertebrates versus non-vertebrates for example [4].

In human hosts, it seems that viruses have a proclivity to become more aggressive via mutations when it becomes easier to infect humans. Indeed, the SARS-CoV-2 we confront today is more contagious and possibly deadlier [1], although not as fast as influenza at mutating, and is not the same as the SARS-CoV-2 we started the pandemic with, and is probably different from the SARS-CoV-2 we will meet in a couple of months. That is why public health measures like distancing, quarantining, maskwearing, and handwashing are all so important to suppress threatening viruses [5].

\section{Virus Mutation versus Human Ideation: The Rivalry}

As a new phase of COVID-19 unfolds, with the availability of remarkably efficient vaccines that have been $[6,7]$ or are soon to be authorized by the

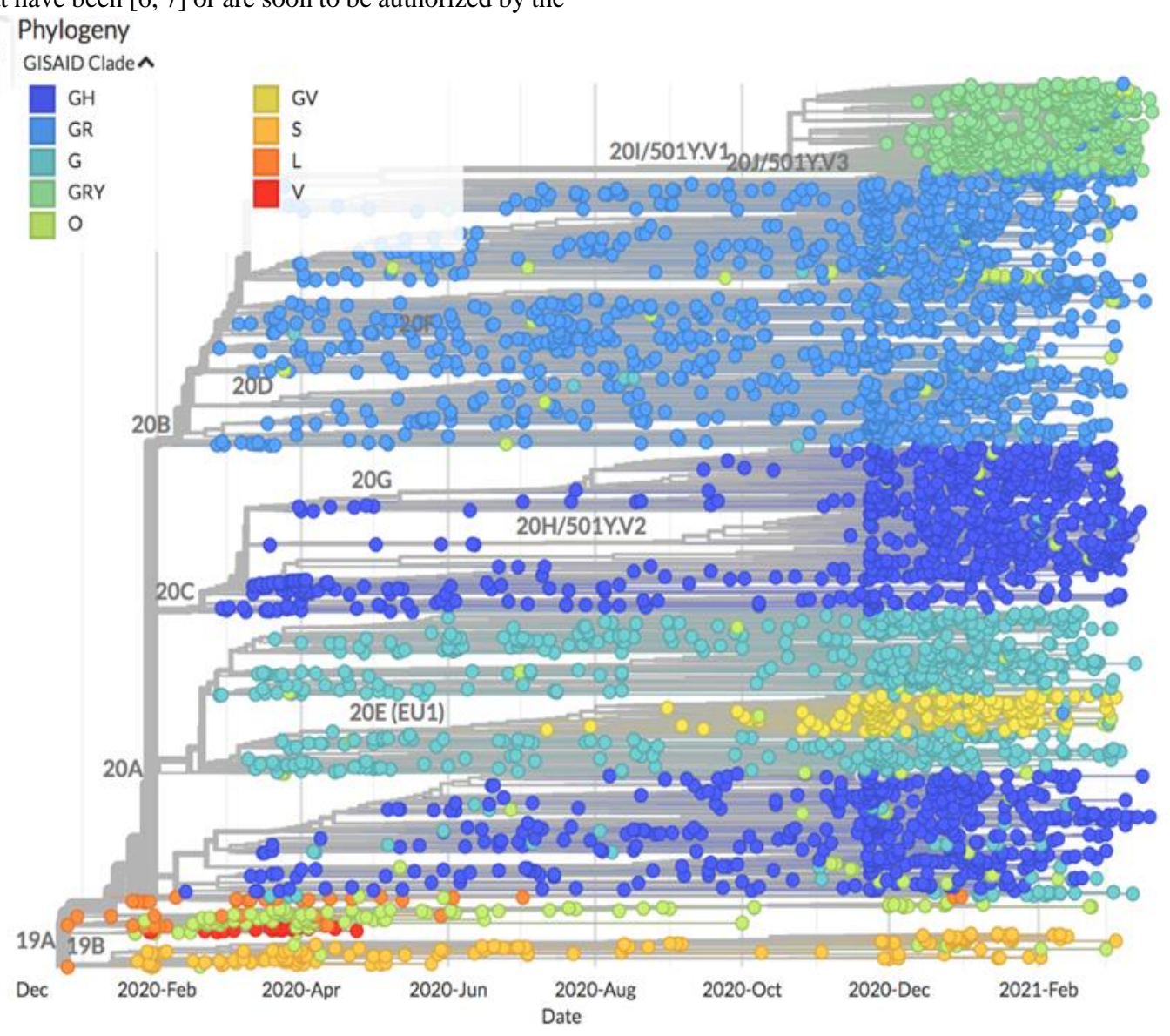

Figure 1: Worldwide genetic surveillance of SARS-CoV-2. The GISAID initiative is collecting all new sequences for SARS-CoV-2 to generate the phylogeny of SARS-CoV-2 [9]. Each dot represents a new mutation; the colors represent the various clades (groupings) [10]. The letters that identify clades correspond to the specific mutation that led to a major split (Caused the SARS-CoV-2 to branch). The $S$, $O$, and $L$ clades were the original clades at the beginning of the pandemic. The $S$ and $O$ clades persisted over time. The L clade produced clades $G$ and $V$. The $G$ clade gave rise to clades $G R$ and $G H$, and more recently $G V$. The GR clade more recently gave rise to clade GRY.

The prioritization of particularly susceptible individuals throughout the vaccination campaign is critical to its success as mutations of SARSCoV-2 seem to occur more frequently in individuals with severe illness and requiring prolonged stay in intensive care units [11]. Patient with type 2 diabetes and obesity are particularly susceptible to COVID-19 severity, a process that might involve surtuin 1 at the molecular level and telomere biology [12]. In a nationwide mass vaccination setting the BNT162b2
FDA [8], it will be fascinating to follow the rivalry between virus mutation and human ideation. Certainly, the newest forms of vaccines based on the transfer of messenger RNA to induce the production of one or more viral proteins by human cells, while being insufficient to produce infecting viral particles, are clearly the most adapted vaccine technology to rapid pathogen mutation activity.

\section{Conclusion}

With a combination of formidable expansion of the genetic surveillance in the U.S. and the world $[9,10]$ Figure 1$\}$ in order to instantly identify SARS-CoV-2 variants capable of overcoming our latest vaccines [1], and the persisting human ability to collectively ideate and adopt novel technologies when threatened, we should be able to contain threats such as human pandemics that would otherwise cause massive destruction to, or even the extinction of, the human species.
mRNA vaccine showed safety and remarkable effectiveness for a wide range of Covid-19-related outcomes [13], a finding consistent with that of the randomized trial $[6,13]$. However, this study also suggests greater benefit of this vaccine in women $[13,14]$. Indeed, risk difference for developing symptomatic COVID-19 between vaccine and control groups was 2.9/1,000 men versus 6.2/1,000 women [13-table 3]. 
Finally, if all of our fellow humans, including the least privileged, can benefit from these vaccines [15], it would be one of the greatest ever achievements of human ideation.

\section{References}

1. Centers for Disease Control and Prevention (2021) https://www.cdc.gov/coronavirus/2019ncov/more/scienceand-research/scientific-brief-emerging-variants.

2. Jacob J, Kelsoe G, Rajewsky K, Weiss U. Intraclonal generation of antibody mutants in germinal centers. Nature (1991) 354: 389-392

3. Goldschmidt-Clermont PJ, Romet Lemonne JL, Fontanet A, Stevenson M. Virus Cooperation, ZIKV Viremia and in Utero Fetus Infection. J Women Health Care Issues. (2019) 2(2): 11. DOI: ncbi.nlm.nih.gov/pmc/articles/PMC7236908/

4. Shi, M., Lin, XD., Chen, X. et al. The evolutionary history of vertebrate RNA viruses. Nature (2018) 556:197-202. DOI: 10.1038/s41586-018-0012-7

5. Goldschmidt-Clermont PJ. COVID-19 real-world data for the US and lessons to reopen business. PLoS Pathogen (2020) DOI: 10.1371/journal.ppat.1008756

6. Polack FP, Thomas SJ, Kitchin N, et al. Safety and efficacy of the BNT162b2 mRNA Covid-19 vaccine. N Engl J Med (2020) 383:2603-2615 DOI: 10.1056/NEJMoa2034577
7. Baden LR, El Sahly HM, Essink B, et al. Efficacy and safety of the mRNA-1273 SARS-CoV-2 vaccine N Engl J Med (2021) 384:403-416 DOI: 10.1056/NEJMoa2035389.

8. Sadoff J, Gray G, Vandebosch A, et al. Safety and efficacy of single-dose Ad26.COV2.S vaccine against Covid-19. N Engl J Med (2021) DOI: 10.1056/NEJMoa2101544.

9. GISAID phylogeny map

https://www.gisaid.org/hcov19-variants/

10. Zoppi L. Viral Clades of SARS-CoV-2. News-Medical, (2021) viewed 08 April 2021, https://www.newsmedical.net/health/Viral-Clades-of-SARS-CoV-2.aspx.

11. Kemp SA, Collier DA, Datir RP et al. SARS-CoV-2 evolution during treatment of chronic infection. Nature (2021) 592:277282 (2021). doi.org/10.1038/s41586-021-03291-y

12. Martins IJ. COVID-19 infection and anti-aging gene inactivation. Acta Scientific Nutritional Health (2020) 4.5:0102.

13. Dagan N, BardaN, KeptenE, et al. BNT162b2 mRNA Covid19 vaccine in a nationwide mass vaccination setting. $\mathrm{N}$ Engl $\mathrm{J}$ Med (2021), DOI: 10.1056/NEJMoa2101765

14. Peters SAE, Woodward M, Jha V, et al. Women's health: a new global agenda BMJ Global Health (2016) ;1:e000080.

15. Campos-Matos I, Mandal S, Yates J, Ramsay M, Wilson J, Lim WS. Maximising benefit, reducing inequalities and ensuring deliverability: Prioritisation of COVID-19 vaccination in the UK. Lancet Regional Health-Europe (2021) ncbi.nlm.nih.gov/pmc/articles/PMC7834926/pdf/main.pdf
This work is licensed under Creative Commons Attribution 4.0 License

To Submit Your Article Click Here: Submit Manuscript

DOI: $10.31579 / 2642-9756 / 058$

\footnotetext{
Ready to submit your research? Choose Auctores and benefit from:

* fast, convenient online submission

* rigorous peer review by experienced research in your field

* rapid publication on acceptance

* authors retain copyrights

* unique DOI for all articles

* immediate, unrestricted online access
}

At Auctores, research is always in progress.

Learn more www.auctoresonline.org/journals/women-health-care-andissues 